POSTER 1-3

\section{Liability Immunity as a Legal Defense for Recent Emergency Medical Service System Litigation}

\author{
*David L. Morgan, MD, Vicky A. Trompler, MD, \\ William R. Trail, JD \\ Division of Emergency Medicine, University of Texas \\ Southwestern Medical Center at Dallas, Dallas, Texas
}

Purpose: To review all recent EMS system civil litigation appellate cases to determine their common characteristics and the number that used liability immunity (sovereign immunity, emergency medical care immunity, or Good Samaritan immunity) as a legal defense.

Methods: The WESTLAW (R) computerized database of legal cases from all state and federal appellate courts was used to obtain all legal cases that named a member of the EMS system as a defendant, involved either a patient-care incident or ambulance collision, and received an appellate court opinion from 1987 to 1992.

Results: Eighty-six cases were found and analyzed. Most cases $(85 \%)$ were related to a patient-care incident, and $71 \%$ of the cases involved a death or significant physical injury. More than $49 \%$ of the patient cases alleged inadequate assessment or treatment, and $27 \%$ alleged delay in ambulance arrival or no ambulance arrival. There were 11 cases $(15 \%)$ alleging no transport of the patient to the hospital. Liability immunity was used as a defense in $\mathbf{5 3}$ of the cases. The appellate courts ruled in favor of $68 \%$ of the defendants that did not use an immunity defense, and in favor of $72 \%$ of those that did use liability immunity.

Conclusion: There have been a large number of recent appellate cases involving EMS systems. The common characteristics of many of these cases demonstrate the need for providing rapid ambulance arrival, proper assessment and treatment, and rapid patient transportation to a hospital. Although liability immunity was used as a legal defense by most EMS system defendants, the appellate court outcome was similar regardless of its use.
POSTER 2-31

\section{Emergency Medical Services Liability Litigation: 1987-1992}

\author{
David Morgan, MD, *Michael Wainscots, $M D$, \\ Heidi Knowles, BA \\ Division of Emergency Medicine, University of Texas \\ Southwestern Medical Center at Dallas, Texas
}

Purpose: To review a nationwide sample of recent EMS liability litigation to determine common characteristics. There have been no published studies of nationwide EMS legal cases, and the last local EMS legal case study was completed in 1987.

Methods: A computerized database of trial court cases was used to obtain a convenience sample of legal cases tried against EMS agencies, EMS employees, or EMS volunteers from 1987 to 1992 . The following characteristics were reviewed for each case: date, location, plaintiff age and gender, original problem, ambulance collision or patient-care incident, primary injury, negligence allegation, codefendants, and outcome.

Results: There were 76 legal cases that met the inclusion criteria. Half of these cases involved an ambulance collision (AC), and half involved a patient-care encounter (PC). Thirty (79\%) of the plaintiffs in the AC cases were other motorists, and $35(92 \%)$ of the plaintiffs in the PC cases were EMS patients. Almost half of the cases named an individual (usually an EMT or paramedic) as a codefendant. Thirty-one $(41 \%)$ of the cases were closed without payment to the plaintiff. There were five cases with plaintiffs awards or settlements greater than [US] $\$ 1,000,000$. Most $(71 \%)$ of the ambulance collisions occurred in an intersection or when one vehicle rearended another vehicle. The most common negligence allegations were arrival delay, inadequate assessment or treatment, patient transport delay, or no patient transport.

Conclusion: The common characteristics of this sample of recent EMS legal cases may provide risk-management recommendations to decrease the legal risk to EMS providers. 